\title{
ESTUDOS CULTURAIS E LITERATURA
}

\section{Klaus EGGENSPERGER - UFPR}

RESUMO: O ensaio discute algumas relações entre estudos culturais e literatura. Vista de uma perspectiva histórico-cultural, a literatura perdeu, na segunda metade do século XX, o seu status como mídia principal. Os Estudos Culturais foram uma resposta a isso, investigando a produção, a circulação e ao consumo de bens simbólicos das mais diversas áreas em seus respectivos contextos. Para uma formação cultural na sua dimensão de formação humana, porém, a literatura continua a ser indispensável.

PALAVRAS-CHAVE: estudos literários; estudos culturais; indústria cultural; mídia.

ABSTRACT: The essay discusses some relations between cultural studies and literature. From a cultural history's point of view, literature has lost its status as dominant media in the second half of the twentieth century. Dedicating itself to the study of the production, circulation and consumption of cultural goods of many realms, cultural studies has been an answer to this development. However, for a cultural education in its dimension of human formation, literature continues to be essential.

KEYWORDS: literary studies; cultural studies; culture industry; media

\section{CONSIDERAÇÕES INICIAIS}

Sob a perspectiva da sociologia cultural, tentamos neste artigo um esboço do rumo da literatura ocidental moderna dos últimos três séculos. Começamos com um exemplo instrutivo extraído de Jorge Amado, portanto, da literatura brasileira. Mas no centro de nossa avaliação estão as transformações históricas que resultaram na atual sociedade capitalista de consumo. Na Europa este desenvolvimento foi acompanhado de certa crítica cultural (lembremos a tradição alemã) e resultou na formação daquele conjunto interdisciplinar denominado cultural studies, basicamente por contribuições anglo-americanas. Em consequência da perda da primazia da literatura como mídia principal, os Estudos Culturais dedicam-se à investigação de bens simbólicos das mais diversas áreas culturais no contexto social contemporâneo. Fica o desafio para o ensino de literatura, que aqui só podemos apontar: mostrar que a ocupação com obras literárias dos séculos passados merece o esforço do leitor atual, pois o enriquece tanto na sua dimensão humana quanto 
na sua capacidade crítica em lidar com as contradições de um mundo cada vez mais complexo e confuso.

\section{MALVINA E OS ROMANCES PROIBIDOS}

Em Gabriela, cravo e canela, a rica, mas provinciana Ilhéus dos anos vinte retratada por Jorge Amado, ainda não sofreu a presença dos meios de comunicação social de massas que tanto influenciaram a vida cotidiana no século passado. O cinema já existia, mas possuía um papel periférico; o rádio ainda não havia chegado ao sul da Bahia, e a TV nem havia sido inventada. No romance, que retrata em detalhes a vida da cidade, a comunicação individual e social ainda não é midiatizada: acontece quase que exclusivamente "olho no olho" nas ruas, nas praças, nos clubes e nos bares, como no famoso Bar Vesúvio. Quanto ao "universo Gutenberg”, existem um diário impresso e uma papelaria/livraria, cujo dono, João Fulgêncio, representa a minúscula classe média instruída da comunidade. A grande massa da população é analfabeta, e os homens da elite não costumam ler romances ou poesias, mas permitem às mulheres e filhas a leitura, a fim de se distraírem em casa, enquanto eles se divertem nos bares e bordéis. Ao mesmo tempo, a técnica de ler e escrever serve para diferenciar a elite e a classe média do povo, e a literatura promete aquilo que Bourdieu chama de capital simbólico. Daí resulta um dos conflitos entre Nacib e Gabriela, já casados: o comerciante pretende participar da leitura pública do "eminente e inspirado poeta Dr. Argileu Palmeira" na intendência da cidade, não obstante, sua esposa prefere o popular, querendo assistir ao espetáculo de um pequeno circo ambulante. Interesse em literatura nenhum dos dois tem, mas Nacib, com a sua clientela de coronéis e doutores, sente a obrigação social de comparecer a tal evento literário.

Das diversas personagens femininas no romance, há duas que conseguem escapar à lógica machista do patriarcado tradicional, que determina a vida de todos ilheenses. Uma delas é a protagonista que dá nome ao título da obra, Gabriela. A outra é Malvina, filha rebelde de um coronel, pertencendo assim à elite local. Essa jovem não se conforma com seu provável destino de, como ela mesma formula, enterrar-se na cozinha de algum fazendeiro, que nem poderia escolher. Informa o narrador: 


\begin{abstract}
Malvina odiava aquela terra, a cidade de cochichos, do disse-que-disse. Odiava aquela vida e contra ela passara a lutar. Começara a ler, João Fulgêncio a encaminhava, recomendando-lhe livros. Descobriu outro mundo mais além de Ilhéus onde a vida era bela, onde a mulher não era escrava. As grandes cidades onde podia trabalhar, ganhar o seu pão e sua liberdade. Não olhava para os homens de Ilhéus, Iracema a chamava de virgem de bronze, o título de um romance, porque ela não tinha namorados. (AMADO, 2005, p. 219)
\end{abstract}

Malvina chega a namorar um homem de fora, o engenheiro responsável pela drenagem da barra, maior projeto da modernização na região. Mais tarde consegue fugir da cidade para ganhar a sua vida em São Paulo e estudar. O que interessa aqui é a relação afirmativa que Malvina tem com a literatura, diferentemente da grande maioria dos ilheenses. Gosta de ler e não aceita a proibição de certos títulos para moças solteiras, como O Crime do Padre Amaro de Eça de Queiroz. Seu pai, representante do patriarcado tradicional, comenta: "Livro só de colégio, os outros não prestam para nada, só servem para desencaminhar" (AMADO, 2005, p. 214). Do seu ponto de vista, tem plena razão, e os acontecimentos em torno de sua filha comprovam isso. Para uma moça da elite local saber que existem "outros mundos além de Ilhéus", no sentido literal e no sentido figurativo, só restam os romances, proibidos ou não. Parece que, mesmo num país como o Brasil, onde o livro impresso nunca foi mídia principal para uma maioria, a literatura tinha um papel importantíssimo para determinadas camadas da população. A literatura pode ser essencial para o desenvolvimento do indivíduo, do seu ego; tem, portanto, um papel importante para sua individuação. A literatura pode afirmar ou questionar normas e valores tradicionais do grupo; neste sentido apoia a socialização dos indivíduos. O episódio de Malvina consegue demonstrar bem isso, e Jorge Amado é um dos melhores exemplos de como a obra de um autor ajuda a formar uma certa coerência cultural. Gabriela é, sem dúvida, a personificação literária da mulata brasileira; ela tem seu lugar no imaginário brasileiro até hoje e, com isso, um papel no processo da aculturação ${ }^{1}$ de indivíduos, quer dizer: no processo que os indivíduos compartilham para se integrarem ao todo que se chama 'cultura brasileira'.

\title{
3. DOIS SÉCULOS E MEIO BURGUESES
}

\footnotetext{
${ }^{1}$ Os três conceitos individuação, socialização e aculturação encontram-se em ABRAHAM/KESPER (2006, cap. 1.1). Sobre a mulata como objeto social, "símbolo de uma sociedade (que se quer) mestiça", cf. o conciso artigo de Mariza CORRÊA (1996).
} 
Cabe aqui uma primeira demarcação teórica. O termo "indivíduo" designa simplesmente uma entidade humana (física, afetiva, cognitiva), enquanto "sujeito" compreende a forma cultural toda em que o indivíduo se torna um ente social através de práticas e discursos (cf. a definição em RECKWITZ 2008a, p. 17), passa então por individuação, socialização e enculturação. O conceito de "sujeito" sempre foi ambíguo. Em português, uma das acepções para "sujeito" pode ser "indivíduo dependente ou subordinado" (cf. Dicionário Eletrônico Houaiss), conservando-se o significado original do particípio latino "subjectus", do verbo "subicere" que, por sua vez, é uma composição de "sub" e "iacere", subjugar. Esse significado - sujeito como indivíduo subordinado - preserva-se em seus derivados, como "sujeitar" e "sujeição". Sob outra perspectiva, o sujeito é um agens, um "eu pensante" (um agente), uma entidade autônoma e ativa em oposição a um objeto, conceito este que vem do pensamento filosófico europeu desde Descartes e ganha relevância máxima no idealismo alemão. As análises contemporâneas do conceito "sujeito" refletem tal ambiguidade do campo semântico: os indivíduos tornam-se sujeitos aparentemente autônomos, reconhecidos por si mesmos e por outros, ao se sujeitarem aos códigos simbólicos, às rotinas físicas e psíquicas, às regras e práticas sociais em vigor. A teoria sociológico-cultural do sujeito surgiu com pensadores franceses das décadas de sessenta e setenta como Althusser e Foucault. Muitos trabalhos de Foucault visam uma "história do sujeito", investigando a formação do sujeito moderno. Paralelamente, desenvolveu-se uma tradição de pesquisa histórico-cultural, que tem investigado as condições culturais específicas dos séculos passados, quando surgiram formas determinadas de sujeitos.

Obras de referência como a História da vida privada, de Philippe Ariès e Georges Duby (1985-1987), ressaltam a importância das práticas de leitura e escrita e do valor das belas-letras a partir da Renascença. Sabemos que a literatura, como mídia principal, tinha seu auge nos países europeus com maior índice de alfabetização durante os séculos XVIII e XIX e a primeira metade do século XX. Mas já nos séculos anteriores, dentro da burguesia, classe social em ascensão, surgiu uma nova cultura literal. O sujeito burguês forma-se como um ego íntimo, que se define através de relações pessoais. Palavras-chave desse processo são sensibilidade, amizade, autocontrole, privacidade, casamento como relação íntima e exclusiva, família, entre outros. Intimidade e autoconhecimento constituem-se em relação com o desenvolvimento de práticas literárias como a leitura silenciosa e a escrita autógrafa, que abrange cartas, diários íntimos, 
confissões de modo geral (v. CHARTIER, 2009). "Cultura significa o domínio da subjetividade social”, como formula o crítico inglês Terry Eagleton, “[...] e a Literatura tinha um papel-chave na formação dessa subjetividade" (EAGLETON, 2005a, p. 62; cf. também SCHULTE-SASSE 2010), servindo como orientação na vida de um indivíduo da classe média. Além da leitura empática de romances, da produção de poemas próprios, da visita ao teatro local, também tinham importância para a classe média as práticas de produção e recepção de outras artes, principalmente a execução de música no ambiente doméstico e visita a óperas.

O desenvolvimento aqui esboçado trazia também implicações sociológicas. Tradicionalmente, na sua autopercepção, o sujeito burguês se distingue dos aristocratas, de um lado e, do outro, do povo, pela valorização do trabalho, pelos princípios morais - que implicam internalização -, e pela moderação 'natural' (cf. RECKWITZ, 2008b). Esses valores foram amplamente defendidos em discursos literários e não-literários dos séculos passados. O nãoburguês, por sua vez, foi visto como desmedido, artificial e parasitário (no caso dos aristocratas), e não tinha, portanto, moral. Na literatura alemã do século XVIII, por exemplo, os grandes autores burgueses como Lessing, Schiller e Goethe denunciaram valores aristocráticos mas, ao mesmo tempo, distanciaram-se das classes populares, do "povão". O mesmo vale para o campo da estética; nesse sentido é instrutiva a crítica dura de Schiller (de 1791) à poesia do seu colega Gottfried August Bürger, que constituiu uma polêmica contra a estética popular e em defesa da autonomia da arte. A partir dessa briga, a dicotomia entre literatura séria, verdadeira, e literatura trivial-popular, estava estabelecida na Alemanha (v. HÜGEL, 2007, p. 99-103). Comenta Theodor W. Adorno: “A arte como domínio separado foi possível, desde o início, apenas como burguesa." (ADORNO, 2002, p. 59).

Todo esse universo ficou para trás, mesmo que restem mais do que vestígios do paradigma literal e, durante a segunda metade do século $\mathrm{XX}$, a literatura perdeu o seu lugar privilegiado em favor de outras mídias. Estudar as práticas culturais da grande massa da população abaixo da classe média: isto era a proposta no início dos estudos culturais na GrãBretanha. O inglês Richard Hoggart, que cunhou o termo cultural studies em 1963, era professor universitário de literatura; o mesmo vale para seu colega Raymond Williams. Juntamente com Edward Thompson estava comprometido com o estudo da cultura popular e operária. Eles "haviam procurado aplicar métodos literários de análise ao estudo de textos 'não-literários', 
assim como descrever, analisar e criticar a cultura popular contemporânea; e o fizeram em termos de duas categorias-chave: classe e nação.” (A. Milner em WILLIAMS, 2007, p. 421). Em 1964 fundaram o famoso Centre for Contemporary Cultural Studies (CCCS) na Universidade de Birmingham. A ênfase em cultura popular e meios de comunicação social de massas permanece até hoje.

O que mudou em termos culturais dos tempos da fundação do CCCS para cá nos países europeus ocidentais? Acredito que a mudança mais importante dos últimos cinquenta anos tenha sido o enfraquecimento, talvez já desaparecimento da cultura burguesa e, ao mesmo tempo, do seu oposto social, da cultura da classe operária. Os estudos culturais como disciplina universitária são uma resposta a isso. Tem-se desfeito da primazia da literatura escrita como a que existiu por, no mínimo, dois séculos e meio no ocidente alfabetizado. Ao mesmo tempo diminui a importância de antigos gêneros literários orais, como a literatura de cordel no Brasil ou os contos de fadas tradicionais. Enquanto na sociedade capitalista dos tempos da revolução industrial o consumo e as mídias de massas eram desconhecidos, ambos agora parecem dominar a nossa vida. Michael Jackson, os Simpsons ou Star Wars de George Lucas têm tido mais relevância para a socialização cultural de muita gente do que a leitura de Rilke, Cervantes ou Shakespeare, inclusive, provavelmente, para a socialização dos estudantes de letras. No Brasil, a importância da MPB para a identidade coletiva não deve ser subestimada; ademais, boa parte da socialização de crianças e adolescentes, que sempre aconteceu em relação direta, interpessoal, com os adultos e com pessoas da mesma idade (como por exemplo na Ilhéus de Jorge Amado), acontece hoje em dia através do contato com a mídia. Se o conceito "sujeito" abrange a forma cultural em que alguém se torna social através de práticas e discursos, os sujeitos modernos são sujeitos midiatizados.

\section{MATERIALISMO CULTURAL, CRÍTICA, CAPITALISMO}

Falemos então brevemente da mídia, sem a menor pretensão de esgotar este assunto. Os meios de comunicação social podem ser entendidos como extensions of man (McLUHAN, Understanding Media: The Extensions of Man, 1964), extensões do corpo humano. Desde os seus primórdios, a humanidade cria o seu próprio universo simbólico; numa perspectiva cultural- 
antropológica, o homem é animal symbolicum (cf. CASSSIRER, 1994, p. 50). Nesse sentido, não pode existir desenvolvimento cultural sem desenvolvimento da mídia e das formas simbólicas circulando dentro dela. Historicamente, a gênese do homem está vinculada à gênese da língua; o segundo grande passo foi o desenvolvimento da escrita e a longa substituição do paradigma oral pelo paradigma da escrita. No século XX, os universos da oralidade e da escrita foram completados pelo paradigma audiovisual e, ultimamente, é o paradigma multimedial que tem ganho importância para os processos de produção e recepção de códigos culturais (cf. RAIBLE, 2006).

Os estudos culturais reagiram a este fenômeno, mas não são simplesmente equiparáveis aos estudos da mídia. A partir de Raymond Williams e Lawrence Grossberg, é possível compreender os estudos culturais enquanto projeto político-pedagógico com a intenção de ler, interpretar e criticar fenômenos culturais no contexto das relações sociais de produção, distribuição e consumo. Bem semelhante à análise do discurso, mas diferentemente de correntes sociológicas como, por exemplo, a teoria de sistemas ou doutrinas literárias, como a teoria da recepção, os estudos culturais estão sempre em uma relação crítica com o poder social; trata-se de uma abordagem intervencionista. Nas palavras de Grossberg:

\begin{abstract}
Os Estudos Culturais são intervencionistas no sentido de tentar utilizar os melhores recursos intelectuais para conhecer mais satisfatoriamente as relações de poder (como a evolução ou o equilíbrio em um jogo de forças) num contexto específico, acreditando que esse conhecimento pode capacitar melhor as pessoas a mudar o contexto e, com isso, as relações de poder. Consequentemente, este projeto é sempre político e partidário, mas a sua política é sempre definida pelo contexto. Além disso, procura entender não somente as organizações de poder mas, também, as possibilidades de luta, resistência e mudança. Parte de princípios contestadores - não como realidade em todos os casos, mas como suposição necessária para um trabalho crítico e para a oposição política. ${ }^{2}$
\end{abstract}

Critical work and political opposition: atrás disso está mais do que o desejo de opção pela militância, a simples decisão moralista de criar e defender um projeto emancipatório. A análise

\footnotetext{
2 "Cultural studies is interventionist in the sense that it attempts to use the best intellectual resources available to gain a better understanding of the relations of power (as the state of play or balance in a field of forces) in a particular context, believing that such knowledge will better enable people to change the context and hence, the relations of power. Consequently, its project is always political, always partisan, but its politics are always contextually defined. Moreover, it seeks to understand not only the organizations of power but the possibilities of struggle, resistance and change. It takes contestation for granted, not as a reality in every instance, but as an assumption necessary for the existence of critical work and political opposition." (GROSSBERG, 2009, p. 31)
} 
semiótica de língua e cultura como fenômenos sociais levam necessariamente à compreensão de que um significado não é inerente às coisas do mundo, sendo sempre o resultado de uma prática de significações (que faz as coisas significarem). Não é o mundo material que transmite os significados, eles são construídos pelos homens e partilhados socialmente no processo históricocultural de uma determinada comunidade. Signos e formas simbólicas são suscetíveis de interpretação e, por isso, podem ser objetos de briga ou luta pelo significado. Toda atividade e todo conhecimento humanos acontecem dentro desse processo; não existe acesso a uma realidade fora das formas simbólicas e fora dos discursos. Ora, se a cultura é entendida como processo de significação, e a política como disputa pelo poder de hegemonizar (i. e. fazer valer) determinadas significações, a separação radical entre política e cultura não se sustenta. Da perspectiva de um materialismo cultural, comenta Raymond Williams: "Se aprendemos a relacionar qualquer trabalho cultural àquilo que aprendemos a denominar 'sistema de signos' [...] também podemos entender que um sistema de signos por si mesmo consiste numa estrutura específica de relações sociais." ${ }^{3} \mathrm{Na}$ perspectiva dos cultural studies, cultura é sempre signifying practice (HALL, 1997), prática significante no processo ativo de significação.

Na tradição alemã, dentro da Teoria Crítica, costuma prevalecer uma outra perspectiva por influência de Adorno. O conceito "indústria cultural" é mais antigo do que o projeto acadêmico dos estudos culturais. Foi elaborado, pela primeira vez, na Dialética do Esclarecimento, obra conjunta de Adorno e Horkheimer, escrita na primeira metade dos anos quarenta em Los Angeles, sendo o capítulo "A indústria cultural - o Iluminismo como mistificação das massas” (ADORNO, 2002, p. 7-74) basicamente de Adorno. Nos Estados Unidos, os intelectuais europeus fugidos do nazismo depararam-se com um capitalismo mais avançado do que na Europa, e com a impressionante produção em série de bens culturais na Broadway ou em Hollywood a fim de gerar lucro. Na Europa, "cultura tinha tradicionalmente significado quase o oposto de capitalismo. O conceito de cultura cresceu como uma crítica à sociedade de classe média, não como um aliado seu" (EAGLETON, 2005b, p. 45). A ideia de que a arte constituía o reverso da utilidade capitalista foi central nos escritos estéticos de Schiller e no romantismo alemão em geral. A verdadeira arte não pode ser medida pelo seu valor de troca e

\footnotetext{
3 "For if we have learned to see the relation of any cultural work to what we have learned to call a 'sign-system' [...] we can also come to see that a sign-system is itself a specific structure of social-relationships" (apud GÖTTLICH, 2009, p. 99).
} 
está em oposição à racionalidade instrumental. Por constituir um livre jogo de espírito e de matéria, estimulando e desenvolvendo as nossas capacidades, a arte opõe-se também aos efeitos de uma divisão do trabalho que diminui o potencial humano. Adorno vem dessa tradição da Kulturkritik alemã, e a combina com elementos de um marxismo não-dogmático.

Combinar Kultur/cultura com Industrie/indústria (ou civilização material) numa expressão só já significava, para os intelectuais da época, uma provocação inusitada. O conceito serviu para a análise das mudanças culturais dentro do sistema capitalista, que havia entrado numa fase nova que a sociologia atual chama de fordismo. Na perspectiva da Teoria Crítica, a indústria cultural do novo século pôs fim à resistência e protesto, qualidades intrínsecas à obra de arte tradicional. Durante os séculos burgueses, a arte estava submetida a uma aporia produtiva:

\begin{abstract}
ela deve ser autônoma e contrapor-se à sociedade, ainda que, ao afirmar-se como autônoma, se apresente como ideologia. O caráter ambíguo da arte consiste em ela ser ao mesmo tempo autônoma e fato social. Ela 'critica a sociedade pela sua simples existência' [Adorno]. A arte institui algo que escapa à lógica da sociedade de trocas, onde tudo existe em função dessas trocas. (SELIGMANN-SILVA, 2009, p. 105)
\end{abstract}

Ao invés disso, o rádio, as revistas e o cinema se esforçaram para sincronizar os indivíduos com o todo, o que Adorno qualificou como "falsa identidade do universal e do particular" (ADORNO, 2002, p. 8). Conclusão: "a indústria cultural não sublima, mas reprime” (ADORNO, 2002, p. 35).

Outros autores da Escola de Frankfurt e amigos de Adorno, como Walter Benjamin e Siegfried Kracauer, porém, não condenam as novas tecnologias de mídia e as mercadorias culturais transmitidas por elas. Benjamin parece lamentar a destruição da aura da obra de arte no seu famoso ensaio "A obra de arte na era da sua reprodutibilidade técnica", mas mostra-se, ao mesmo tempo, entusiasmado pelos "novos espaços de liberdade abertos pelo filme" (BENJAMIN, 1994, p. 190), elogiando Charles Chaplin e as primeiras animações de Disney com o camundongo antropomórfico Mickey Mouse, que rapidamente ganhou fama no mundo inteiro. E escritores vanguardistas na Alemanha pré-nazista, como Alfred Döblin e Bertolt Brecht, não só elaboraram roteiros para o cinema, mas também fizeram experimentos com a rádio-peça dentro da novíssima mídia do rádio.

Da produção fordista de massa dos tempos de Adorno, Benjamin e Brecht, chegamos aos tempos pós-fordistas e suas novas tecnologias digitais. Nos países capitalistas mais ricos, a economia de escala evoluiu para algo que poderia ser chamado de economia pródiga ou, talvez, 
economia estética. Grande parcela da produção consiste em bens supérfluos dos quais ninguém precisa realmente, e boa parte do consumo também está desvinculada de necessidades materiais, servindo para a realização de um status social, um habitus. A teoria marxista clássica diferencia entre valor de uso das mercadorias e seu valor de troca; parece que a essas categorias devemos juntar um valor estético ou um valor de encenação (v. BÖHME, 2008).

Os bens e serviços padronizados são vendidos em grande escala, mas oferecidos como se fossem autênticos e singulares, como um produto ou atendimento personalizado. A promessa vinculada a um determinado produto deve necessariamente ser enganadora ou, ao menos, exagerada. Comenta Zygmunt Bauman:

\begin{abstract}
A sociedade de consumo prospera enquanto consegue tornar perpétua a não-satisfação de seus membros. [...] Do contrário, a busca acaba ou o ardor com que é feita (e também sua intensidade) caem abaixo do nível necessário para manter a circulação de mercadorias entre as linhas da montagem, as lojas e as latas do lixo. Sem a repetida frustração dos desejos, a demanda de consumo logo se esgotaria e a economia voltada para o consumidor ficaria sem combustível. (BAUMAN, 2008, p. 64)
\end{abstract}

Stephen Miles chama isso consumerism as a way of life (MILES, 2009) - parece que o capitalismo avançado engoliu, de certa maneira, a crítica estética, que muitos intelectuais sempre a ele aplicaram em nome da autenticidade, criatividade, prazer, individualismo, auto-realização etc. Conceitos como esses perderam seu poder de contestar a lógica do mercado. Mais: são oferecidos nos mercados, fazem parte da "identidade incluída" dos bens de consumo, da sopinha instantânea no supermercado até o mais novo cabriolé da BMW. São exigidos também da mãode-obra procurada por empresas no mercado de trabalho. De um lado temos, então, a estetização da mercadoria e, de outro, a cultura é comercializada em proporções até agora desconhecidas. Nas artes visuais atuais, o valor estético de uma obra e seu valor comercial já são praticamente idênticos. Felizmente para os gestores dos grandes fundos de investimento, existe um índice exclusivamente dedicado à arte: o Mei-Moses fine art index. Desenvolvido por dois professores da Stern School of Business (New York University), este índice registra sistematicamente o valor pelo qual as obras de arte são vendidas nos principais leilões mundiais. Através desse índice pode-se verificar que o investimento em arte proporcionou um retorno nos últimos 50 anos superior ao investimento em obrigações.

Perante essa situação fala-se até em "capitalismo cultural” (v. NECKEL, 2008) como formação social, onde cultura e economia capitalista se confundem. Olhando-se para as 
sociedades ocidentais dos anos sessenta e setenta do século passado, confirma-se um velho princípio materialista ainda dos tempos de Marx e Engels: quando mudam produção e consumo, muda a forma da socialização dos sujeitos. É fácil entender que a celebração do consumo exige sujeitos consumistas que apreciam o prazer e um estilo individual ${ }^{4}$. Agora importa ser diferente dos outros, não ser igual, e ganhar com isso aceitação social, o que não deixa de ser um certo paradoxo. Parece altamente irônico, porém, que tenha sido na Europa ocidental e na América do Norte que dois movimentos culturais críticos ao capitalismo, a Pop-art e a contracultura juvenil, prepararam o terreno fértil para o consumismo atual. A Pop-art partiu do princípio "que o consumismo havia mudado a aparência do mundo, talvez até a natureza dessa aparência, e que a arte deveria desenvolver novos conteúdos correspondentes e novas formas." (FRANCIS, 2005, p. 18; tradução própria). Com isso caíram as últimas fronteiras entre a arte moderna e o entretenimento, a cultura de massas da vida quotidiana. Logo em seguida veio o grande movimento pós-adolescente da contracultura. Sonhava-se com a emancipação total das restrições que as gerações anteriores tinham sofrido, inclusive a geração (da Segunda Guerra) dos próprios pais. Lembra-se Terry Eagleton de

\begin{abstract}
uma década e meia extraordinária, por volta de 1965 a 1980. [...] Foi uma época na qual a sociedade de consumo estava sendo lançada com fanfarras; na qual a mídia, a cultura popular, as subculturas e o culto da juventude surgiram pela primeira vez como forças sociais a serem levadas em conta; e na qual as hierarquias sociais e os costumes tradicionais começavam a ser alvo de ataques satíricos. [...] Tínhamos mudado de esforçados, autodisciplinados e submissos para relaxados, hedonistas e insubordinados. (EAGLETON, 2005b, p. 44)
\end{abstract}

$\mathrm{Na}$ literatura e nas artes visuais existem muitas obras que, de uma maneira ou outra, trabalharam ou documentaram essa mudança paradigmática. Visto de hoje, de certa distância temporal, notamos que a reconstrução do capitalismo começou com a contracultura pósadolescente dos anos 60 e 70, que depois virou mainstream. Mudaram-se as relações dos gêneros, a maneira de se lidar com emoções e afetos, recombinaram-se as relações de amizade e de trabalho. Além do consumismo estético, estabeleceu-se a ideologia de que cada indivíduo é seu próprio empreendedor e empresário em relação às suas habilidades físicas, racionais e emocionais. Para citar um exemplo: no final dos anos noventa, a expressão "inteligência emocional" tornou-se tema de várias monografias e de uma infinidade de discussões em

\footnotetext{
${ }^{4} \mathrm{O}$ sujeito consumista se diferencia por sua capacidade de desenvolver um estilo individual, v. RECKWITZ (2008b, p. 231).
} 
programas de TV, em escolas e mesmo em empresas. O autor do livro Inteligência emocional (1995), Daniel Goleman, redator de ciência do The New York Times, divulgou a idéia de que seja desejável e possível nos motivarmos e gerirmos bem as emoções dentro de nós e nos nossos relacionamentos, quer dizer: dirigir as nossas emoções a serviço de um objetivo ou uma realização pessoal. Hoje em dia, aponta Zygmunt Bauman,

(...) a identidade é uma pena perpétua de trabalhos forçados. Para os produtores de consumidores ávidos e infatigáveis, assim como para os vendedores de bens de consumo, ela é também uma fonte inesgotável de capital - que tende a se tornar maior a cada investida. Uma vez posta em movimento ainda na tenra infância, a composição e o desmantelamento da identidade se torna uma atividade autopropulsora e autoestimulante. (BAUMAN, 2008, p.142)

\section{ANÁLISE CULTURAL}

No início do século XXI, em países europeus com uma tradição de fomento público às artes e um legado de mídia audiovisual pública, a alta cultura, a cultura com $\mathrm{C}$ maiúsculo (EAGLETON, 2005a), tem sobrevivido em nichos. Subsiste porque ainda serve para se distinguir dos não-entendidos, tanto da plebe quanto dos novos ricos sem nível cultural adequado ao rendimento mensal. Na terminologia de Norbert Elias e Pierre Bourdieu: a alta cultura continua a ser habitus. Obviamente, essa explicação sociológica não está errada (pode ser verificada empiricamente no nosso dia-a-dia universitário, por exemplo), mas é limitada. Alude Terry Eagleton: "A cultura é habitus, (...) mas também é, contraditoriamente, a existência mais sutilmente auto-reflexiva de que somos capazes." (EAGLETON, 2005a, p. 164). Não obstante, cultura - seja erudita ou popular ou de massa - tornou-se quantificável, serializada e negociada; a prioridade comercial transborda em todos os estágios de produção, circulação e consumo de bens simbólicos.

Esta constatação por si pode até parecer banal; no entanto, é altamente desafiador discutir as consequências que resultam disso. Em primeiro lugar, fazemos uma observação a respeito da concepção que se chama análise de texto ou análise de obra. Tradicionalmente, o modo de produção econômica, as relações sociais que resultam disso e o tempo histórico são considerados elementos externos aos produtos culturais. Para a crítica cultural na esteira de Adorno, porém, o social não deve ser separado da obra de arte, do produto cultural em geral, pois habita nela desde dentro, como forma objetiva. Roberto Schwarz talvez seja o representante brasileiro mais 
brilhante dessa abordagem. Os estudos culturais, por sua vez, redimensionaram o campo de pesquisa cultural e um de seus princípios mais importantes é que nenhum produto, nenhuma prática cultural podem ser entendidos fora do seu contexto: “[...] a prática dos Estudos Culturais é radicalmente contextualizadora, eles podem ser descritos como uma disciplina de contextualidade"5 (GROSSBERG, 2009, p. 33; cf. HEPP et. al. 2009, introdução). Defendendo assim a contextualização radical, trata-se de um programa anti-essencial. Nesta perspectiva, interessa menos aquilo que possa ser inerente a uma obra, e mais a situação em que esta foi produzida e recebida.

Para dar um exemplo: uma ópera de Mozart como A Flauta Mágica pode ser entendida como obra-prima burguesa por excelência no que concerne ao enredo, na medida em que conta a história de como um jovem príncipe torna-se sujeito masculino autocontrolado e autônomo, entregando-se ao amor incondicional de uma princesa parceira e subjugando-se aos códigos simbólicos do patriarcado iluminista do século XVIII (cf. EGGENSPERGER, 2010). Obviamente existem outras leituras possíveis, de cunho psicanalítico, leituras feministas etc. Os estudos culturais, porém, sempre prestam atenção na prática. Pergunta-se: qual é o contexto social específico de produção e recepção da peça? Quem está envolvido na produção da peça e por quê? Qual é a motivação do público em assistir à ópera? Assistir à Flauta Mágica à noite, no sofá em frente a um home theatre de última geração, ou numa sala de cinema com amigos, ou no teatro municipal, ou em sala de aula, faz bastante diferença. Igualmente diferentes podem ser as leituras da ópera num contexto cultural brasileiro, comparadas a leituras alemãs ou austríacas. Para a sociologia cultural, cada situação por si apresenta suas regras e seu conteúdo. A dimensão pragmática de uso pode contrabalançar certa "cegueira culturalista", que costuma privilegiar a interpretação das estruturas simbólicas (cultura como texto ou discurso) em detrimento da utilização concreta da obra num contexto específico (cultura como prática). Talvez essa cegueira venha de uma certa déformation professionnelle, pois resulta - em leitores como, por exemplo, professores de literatura - do cumprimento de seus deveres de ofício. Vivemos explicando aos nossos estudantes que a leitura pragmática de uma obra de ficção complexa é ingênua. Enquanto textos não-ficcionais fazem parte de uma determinada situação comunicativa concreta, textos

\footnotetext{
5 "The practice of cultural studies is radically contextualist, and cultural studies might be described as a discipline of contextuality."
} 
ficcionais são descontextualizados e despragmatizados; por isso podem ser lidos e entendidos por leitores de séculos e culturas diferentes. ${ }^{6}$

O exemplo da ópera mozartiana pode demonstrar, também, que o fato de um texto ou um outro artefato cultural ser produzido como mercadoria sob condições capitalistas não implica, de antemão, um julgamento político e, também, não necessariamente um julgamento estético. Justamente a Flauta Mágica, última ópera de Mozart, é uma obra que não teve financiamento da corte ou de um rico mecenas. Foi produzida para o teatro do ator, libretista e empresário cultural Schikaneder, dono do Theater auf der Wieden num subúrbio de Viena, para uma plateia bem diversa de todas as camadas da população (cf. EGGENSPERGER, 2010). Essa grande obra artística da humanidade foi, ao mesmo tempo, uma das primeiras criadas sob a condição de ser um sucesso comercial. Na situação histórica da Europa central nos primeiros anos da revolução francesa, tudo que um gênio como Mozart almejava era poder comercializar suas obras num mercado isento de restrições, viver como livre artista, ao invés de depender da tutela de um aristocrata ignorante.

Quando se discute sobre mídia e produtos culturais, não há como ignorar a famosa frase de Marshall MacLuhan, the medium is the message, de 1964. Literalmente entendido, não faz muito sentido, mas aponta para o problema central da relação forma - conteúdo. Já no século XIII, o escolástico Tomás de Aquino enunciava: omne, quod recipitur in aliquo, est in eo per modum recipientis (apud RAIBLE, 2006, p. 15), o que pode ser traduzido com "tudo é recebido segundo o modo do recipiente". Quer dizer: o recipiente imprime cunho no conteúdo que armazena. Do ponto de vista dos estudos culturais, interessa menos a mídia em si, os diversos tipos de transmitir comunicação, da voz humana aos dispositivos de armazenamento por meios eletrônicos como o pen drive. A atenção está mais concentrada nas formas culturais ou formas simbólicas, em que a comunicação acontece:

Formas simbólicas que foram criadas culturamente e são obrigatórias, como os 'gêneros comunicativos' do dia-a-dia (small talk, fofoca, cumprimento), ou os gêneros textuais da escrita, os 'formatos' da programação televisiva e os gêneros de cinema, são formas que

\footnotetext{
${ }^{6}$ Cf. Karlheinz Stierle (em LIMA, 2002, p. 136): “A recepção quase pragmática dos textos ficcionais encontrou na própria literatura, através de Dom Quijote, o seu monumento. Dom Quixote é o símbolo do leitor em que a ficção se converte em ilusão com tal força que, por fim, põe-se no lugar de sua realidade. Nos inícios do romance banal moderno e da tradição do anti-romance, sempre oposto àquele, coloca-se Dom Quixote como a figura clássica do leitor que não lê, preso que está ao poder ilusório do texto".
} 
nos oferecem orientação, portanto o reconhecimento da unidade na variedade. (RAIBLE, 2006, p. 22; tradução própria)

Neste sentido, os gêneros constituem o lado material das formas simbólicas. São específicos para determinadas mídias; os modelos de categorizar, esquematizar e generalizar variam da conversa cotidiana com o vizinho até a apresentação da própria pessoa no Facebook. Na ciência da literatura, a questão dos gêneros é uma das mais antigas e mais discutidas. Nas últimas décadas tem se desenvolvido uma narratologia intermedial com pesquisas sobre narrativas literárias, acústicas, gráficas, cinematográficas e de toda cultura audiovisual. Se é verdade que não há identidade cultural que não seja contada, a questão da narrativa é uma questão central, indo muito além da literatura tradicional, visto que as estruturas narrativas encontram-se também no cotidiano e nas ciências.

\title{
6. CONSIDERAÇÕES FINAIS
}

Em 2009, o octogenário professor e crítico George Steiner deu uma entrevista ao jornal suíço Neue Züricher Zeitung. Perguntado por que o encontro com a arte hoje em dia seria tão difícil, ele respondeu:

\begin{abstract}
As pessoas estão cansadas. Elas querem ser distraídas, e a indústria do Kitsch fornece o inferior, que é mais fácil. Contudo é anestesia, não tem nada a ver com compreensão, com encontro, com arriscar-se. Sentar-se sozinho, ler, refletir sem barulho, sem som de fundo, tudo isso virou um esforço. Temos apartamentos com paredes finas, onde se escuta a música pop do vizinho. Nos Estados-Unidos, $85 \%$ dos jovens não sabem mais ler sem ouvir música ao mesmo tempo. Os jovens têm medo do silêncio. Alguns dias atrás houve um corte de energia em Cambridge, portanto acendemos velas. Velas não somente trazem luz, mas também um silêncio único; com isso, lê-se com muita concentração. Li em poemas tardios de Hölderlin. De repente, à luz das velas e no silêncio, eles ficaram claros para mim. Talvez fosse somente na minha imaginação, mas comecei a entender coisas que até agora me tinham escapado. (NZZ, 18 de abril de 2009; tradução própria)
\end{abstract}

Parece-me que a problemática até agora discutida está presente nessas palavras de um dos últimos representantes de uma erudição literária burguesa da Europa. A resposta de Steiner tem duas partes: primeiro oferece uma análise do problema, depois evoca toda uma cena cultural concreta. Obviamente, é a qualidade material da situação - o arranjo dos objetos em volta do sujeito leitor, a luz das velas, o silêncio, a concentração nas palavras -, que leva a um entendimento mais profundo da grande poesia clássica/classicista. A cena descrita por Steiner 
lembra uma representação gráfica do século XVIII, mostrando o ainda jovem leitor Goethe no meio de um grupo de amigos em volta de uma mesa numa sala em Weimar:

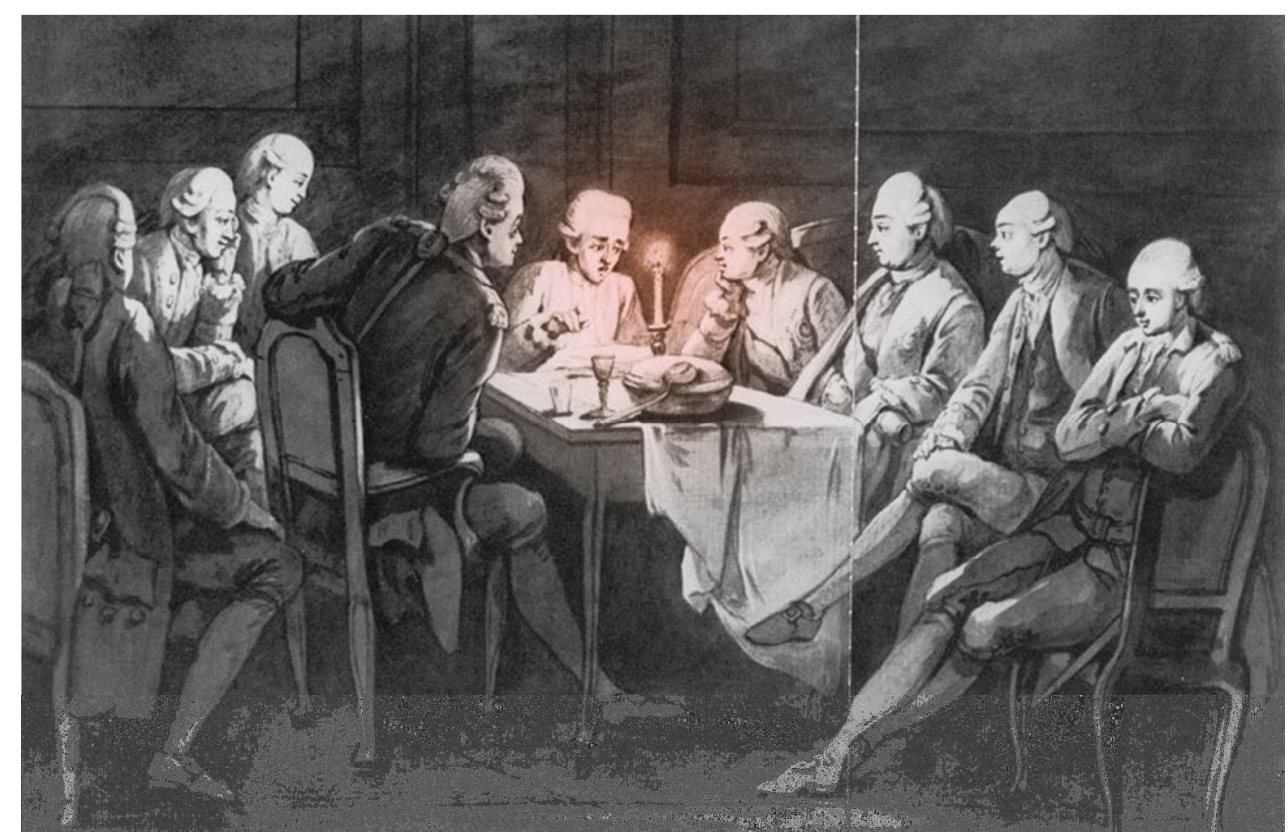

No centro exato do desenho não estão nem o chefe aristocrata do principado, Carl August, nem o jovem gênio Goethe, mas a vela que emite a luz da sabedoria e da empatia. Trata-se de um ato performático como aquele de que nos fala George Steiner e que Georg Melchior Kraus, pintor e desenhista, 230 anos atrás fixou - um ato de epifania que não é mais o aparecimento revelador de Deus mas, sim, o espírito da palavra literária que se manifesta ali. O teórico estruturalista e marxista Louis Althusser costumava citar Blaise Pascal: ajoelhe-se, movimente os lábios para rezar, e você vai crer, vai ter fé. Quer dizer: é o ritual, a praxe dentro de uma instituição definida, que tem a força convincente (cf. ALTHUSSER, 1977, p. 138). ${ }^{7}$

$\mathrm{Na}$ primeira parte de sua resposta, Steiner utiliza-se do vocabulário da Kulturkritik tradicional, fala da indústria do Kitsch e da anestesia. Parece que não faz isso para denunciar, mas para exprimir certa tristeza, saudades dos tempos passados. Um professor de literatura, um leitor em quem já tenha aflorado alguma vez o santo espírito da palavra literária, entende isso muito

\footnotetext{
${ }^{7}$ Sobre a relação entre religião e literatura cf. Heinz Schlaffer, para quem a experiência estética é herdeira das práticas religiosas arcaicas (SCHLAFFER, 2005).
} 
bem. Para os estudos culturais, porém, toda situação cultural exige a consideração de seu contexto sociológico. A cultura como sublimação (v. EAGLETON, 2005a, p.106) não é, por princípio, melhor do que a cultura contemporânea, que funciona mais como gratificação libidinal. Sabemos que atrás da cena simpática com Goethe e Carl August em volta da mesa, escondidos pela sombra da vela, estão as condições culturais e sociais escandalosas do pequeno ducado de Sachsen-Weimar-Eisenach, com uma maioria da população analfabeta, trabalho compulsório dos camponeses, recrutamento forçado de jovens para o exército prussiano etc. A famosa frase de Walter Benjamin, de que "nunca houve um documento da cultura que não fosse também um [documento] da barbárie" (BENJAMIN, 1994, p. 225), ainda não perdeu a sua validade nem no século XXI.

Por isso, os estudos culturais insistem em analisar cultura como prática de produzir significado e sentido, problematizando as representações sociais nos textos e na mídia audiovisual. Mas não se trata de uma crítica pessimista da cultura contemporânea. Entendendo os estudos culturais como um projeto político-pedagógico que deve "começar sempre onde as pessoas estão" (GROSSBERG, 2009, p. 40), não adianta reclamar dos jovens que não sabem mais ler. Ao invés disso, devemos nos abrir a todas as práticas sociais significantes, inclusive as mais populares, sem desistir da crítica. A meta pedagógica chama-se agency no sentido de competência cultural, quer dizer: saber lidar criticamente com os produtos da indústria cultural e com o consumismo cada vez mais dominante. Neste sentido, porém, as leituras de Hölderlin e Rilke, por exemplo, podem ajudar bastante. Para uma formação cultural na sua dimensão de formação humana, a literatura mundial é indispensável. No século XXI, literatura como mídia não tem mais primazia, a contribuição da literatura para a formação de sujeitos diminuiu, e nós, como críticos, temos de reconhecer que existe uma estética além da cultura literária - uma estética de entretenimento, dominante na mídia. Contudo, a fim de mostrar que entretenimento não precisa ser necessariamente simplório e que existem artefatos culturais que vão além da mera distração, nada melhor do que confrontar-se com a memória cultural das gerações anteriores uma memória que sobreviveu em grande parte como literatura.

\section{REFERÊNCIAS}


ABRAHAM, Ulf; KEPSER, Matthis. Literaturdidaktik Deutsch. Eine Einführung. Berlin: Erich Schmidt, 2006.

ADORNO, Theodor W. Indústria cultural e sociedade. São Paulo: Paz e Terra, 2002.

AMADO, Jorge. Gabriela, cravo e canela. Crônica de uma cidade do interior. Rio de Janeiro, São Paulo: Record, ${ }^{92} 2005$.

BAUMAN, Zygmunt. Vida para consumo: a transformação das pessoas em mercadoria. Rio de Janeiro: Jorge Zahar, 2008.

BENJAMIN, Walter. A obra da arte na era de sua reprodutibilidade técnica. Primeira versão. In: BENJAMIN, Walter. Magia e técnica, arte e política. Ensaios sobre literatura e hsitória da cultura (Obras escolhidas, vol. 1). São Paulo: Brasiliense, ${ }^{7} 1994$, p. 165-196.

BÖHME, Gernot. Zur Kritik der ästhetischen Ökonomie. In: MAASE, 2008, p. 28-41.

CASSIRER, Ernst. Ensaio sobre o homem - Introdução a uma filosofia da cultura humana. São Paulo: Martins Fontes, 1994.

CEVASCO, Maria Elisa. Literatura e estudos culturais. In: BONNICI, Thomas; ZOLIN, Lúcia Osana (org.). Teoria Literária: abordagens históricas e tendências contemporâneas. Maringá, Eduem, 2009, p. 319-325.

CHARTIER, Roger (ed.). História da vida privada, 3: da Renascença ao Século das Luzes. São Paulo: Companhia das Letras, 2009.

CORRÊA, Mariza. Sobre a invenção da mulata. Cadernos Pagu (6-7) 1996, p. 35-50.

DUARTE, Rodrigo. Indústria cultural: uma introdução. Rio de Janeiro: Editora FGV, 2010.

EAGLETON, Terry. A ideia de cultura. (original inglês: 2000). São Paulo: Editora UNESP, 2005. [EAGLETON 2005a]

EAGLETON, Terry. Depois da teoria. Um olhar sobre os Estudos Culturais e o pósmodernismo. (original inglês: 2003). Rio de Janeiro: Civilização Brasileira, 2005. [EAGLETON 2005b]

EGGENSPERGER, Klaus. “... porque um preto é feio.” A Flauta Mágica de Mozart e a figuração do Outro. In: Crítica Cultural 5 (1), 2010, 105-128. Online: http://www3.unisul.br/paginas/ensino/pos/linguagem/critica/0501/00.htm (20/05/2011)

FRANCIS, Mark (ed.). Pop. Survey by Hal Forster. London, New York: Phaidon, 2005. 
FREDERKING, Volker; KROMMER, Axel; MAIWALD, Klaus. Mediendidaktik Deutsch. Eine Einführung. Berlin: Erich Schmidt, 2008.

GÖTTLICH, Udo. Raymond Williams: Materialität und Kultur. In: HEPP; KROTZ; THOMAS, 2009, p. 94-103.

GROSSBERG, Lawrence. Cultural Studies - What's in a Name (one more Time). In: HAMMER/KELLNER, 2009, p. 25-48.

HALL, Stuart (ed.). Representation: Cultural Representations and Signifying Practices. London: Sage, 1997.

HAMMER, Rhonda; KELLNER, Douglas. Media/cultural studies: critical approaches. New York: Peter Lang, 2009.

HEPP, Andreas; KROTZ, Friedrich; THOMAS, Tanja (ed.). Schlüsselwerke der Cultural Studies. Wiesbaden: VS Verlag für Sozialwissenschaften, 2009.

HEPP, Andreas; WinTER, Rainer (ed.). Kultur - Medien - Macht. Cultural Studies und Medienanalyse. Wiesbaden: VS Verlag für Sozialwissenschaften, 2008.

HÜGEL, Hans-Otto. Lob des Mainstreams. Zu Begriff und Geschichte von Unterhaltung und Populärer Kultur. Köln: Herbert von Halem, 2007.

LIMA, Luiz Costa (ed.). A literatura e o leitor: textos de estética da recepção. Hans Robert Jauss... et. al. $2^{\text {a }}$. ed. revista e ampliada. Rio de Janeiro: Paz e Terra, 2002.

MAASE, Kaspar (Hg.). Die Schönheiten des Populären. Ästhetische Erfahrung der Gegenwart. Frankfurt, New York: Campus, 2008.

MILES, Stephen. Consumerism - as a way of life. London: Sage Publications, 2009.

NECKEL, Sighard. Flucht nach vorn: Die Erfolgskultur der Marktgesellschaft. Frankfurt a. M.: Campus, 2008.

RAIBLE, Wolfgang. Medien-Kulturgeschichte. Mediatisierung als Grundlage unserer kulturellen Entwicklung. Heidelberg: Winter, 2006.

RECKWITZ, Andreas. Subjekt. Bielefeld: transcript, 2008. [RECKWITZ 2008a]

RECKWITZ, Andreas. Unscharfe Grenzen. Perspektiven der Kultursoziologie. Bielefeld: transcript, 2008. [RECKWITZ 2008b]

RYAN, Marie-Laure (ed.). Narrative across Media: The Languages of Storytelling. Lincoln, London: University of Nebraska Press, 2004. 
RYAN, Michael (ed.). Cultural Studies: An Anthology. Malden: Blackwell Publishing, 2008.

SCHLAFFER, Heinz. Poesie und Wissen. Die Entstehung des ästhetischen Bewusstseins und der philologischen Erkenntnis. Frankfurt a. M.: Suhrkamp, 2005.

SCHULTE-SASSE, Jochen. Medien/medial. In: Barck, Karlheinz et. alii (ed.). Ästhetische Grundbegriffe. Historisches Wörterbuch in sieben Bänden. Band 4. Stuttgart, Weimar: Metzler, 2010 [2002], p. 1-38.

SELIGMAN-SILVA, Márcio. A Atualidade de Walter Benjamin e de Theodor W. Adorno. Rio de Janeiro: Civilização Brasileira, 2009.

STEINER, George. Entrevista com a Neue Zürcher Zeitung, 18 de abril de 2009. http://www.nzz.ch/nachrichten/kultur/literatur und kunst/eine gute lektuere ist ein dank an d en_text_1.2424447.html (20/05/2011).

STEINERT, Heinz. Kulturindustrie. Münster: Westfälisches Dampfboot, 2008. [Ed. em inglês: Culture Industry. Malden: Blackwell Publishing, 2003.]

WILLIAMS, Raymond. Palavras-chave: um vocabulário de cultura e sociedade. São Paulo: Boitempo, 2007. 